\title{
COMPLEMENTARITY OF HISTORIC BUILDING INFORMATION MODELLING AND GEOGRAPHIC INFORMATION SYSTEMS
}

\author{
X. Yang*, M. Koehl, P. Grussenmeyer, H. Macher \\ Photogrammetry and Geomatics Group, ICube Laboratory UMR 7357, INSA Strasbourg, France \\ (xiucheng.yang, mathieu.koehl, pierre.grussenmeyer, helene.macher)@insa-strasbourg.fr
}

\author{
Commission V, WG V/2
}

KEY WORDS: Cultural Heritage, Historic Building Information Modelling, 3D Models, Parametric Objects, Geometric Modelling, Library, Level of Details

\begin{abstract}
:
In this paper, we discuss the potential of integrating both semantically rich models from Building Information Modelling (BIM) and Geographical Information Systems (GIS) to build the detailed 3D historic model. BIM contributes to the creation of a digital representation having all physical and functional building characteristics in several dimensions, as e.g. XYZ (3D), time and nonarchitectural information that are necessary for construction and management of buildings. GIS has potential in handling and managing spatial data especially exploring spatial relationships and is widely used in urban modelling. However, when considering heritage modelling, the specificity of irregular historical components makes it problematic to create the enriched model according to its complex architectural elements obtained from point clouds. Therefore, some open issues limiting the historic building 3D modelling will be discussed in this paper: how to deal with the complex elements composing historic buildings in BIM and GIS environment, how to build the enriched historic model, and why to construct different levels of details? By solving these problems, conceptualization, documentation and analysis of enriched Historic Building Information Modelling are developed and compared to traditional 3D models aimed primarily for visualization.
\end{abstract}

\section{INTRODUCTION}

With the trend of information technology, 3D modelling has been dedicated to represent and visualize the object, and one of its modern applications is the heritage conservation. Initial 3D modelling is dedicated to visualization especially to provide the user with full web-access (Gabellone, 2009). These first models are actually just $2.5 \mathrm{D}$ models without $3 \mathrm{D}$ information. It is obvious that visualization is not enough for historic buildings and their management. Conservation professionals do not only need to navigate through documents but also need to perform spatial and multi-criteria queries in a virtual 3D environment for taking decisions. Even if the buildings have some critical evolutions or collapses, how can the users, historians, managers have the possibilities to reconstruct and to analyse them?

In response to the question, two enriched "information" modelling techniques - Building Information Modelling (BIM) and Geographical Information System (GIS) have been widely developed to document and manage the geometry, structural, and semantic information. BIM is defined by Bentley (2016) as "modelling of both graphical and non-graphical aspects of the entire building life cycle in a federated database management system". BIM is therefore called a rich model because all objects in it have properties and relationships and this information can be used for data mining to develop simulations or calculations using the model data (Arayici, 2008). GIS "lets us visualize, question, analyse and interpret data to understand relationships, patterns and trends" (ESRI, 2016). GIS modelling is rich in information because it is a computer-based tool to analyse and manage spatial, attribute, and relationship information among the elements.

Both BIM and GIS represent opportunities for heritage digital modelling and conservation management. BIM is first used as a management of life-cycle construction process in architectural industry, which is suitable to parametrically model the historical building based on documentation data and record the temporal representation of heritage sites. "As-built" BIM utilize photogrammetry and laser scanning data to reconstruct the (historic) buildings based on reverse engineering. It aims to rebuild accurately current historic geometric models and to generate semantically rich representation with additional spatial relationships and attribute information. When addressing the spatial relationship and query-based problems, GIS allows users to create interactive query, analysis, and spatial information edition. GIS modelling has also been used to procedurally model modern residential scenes (Schwarz \& Müller, 2015).

Till now, it has been widely accepted to create accurate geometric models by 3D graphics, remote sensing and computer science techniques, to incorporate additional attributes and spatial relationships in BIM environment and manage the enriched model in GIS environment.

Anyway, to introduce BIM and GIS into the heritage modelling process, it still requires a methodological discussion and practical experimentation in order to obtain detailed models of irregular historical objects, especially from manual modelling to semi-automatic/automatic modelling. Now, the heritage modelling process is just in an early stage and some specificities are expected to be developed. This paper summarizes the

\footnotetext{
* Corresponding author
} 
current trend in historic modelling combining BIM and GIS, and then analyses some open and key issues related to the complexity, accurate geometric modelling and different level of details. The difficulty of historic building modelling compared to the classical modelling lies in its complex elements, which makes conventional approaches and software invalid. The accurately geometric modelling becomes difficult owing to the complex surface structures, which is necessary and essential to heritage conservation. Besides, the obtained model should possess different level of details that can be accessed by different user's needs.

\section{RELATED WORKS}

The classical 3D visualization-aimed building models cannot provide detailed information about the entity and its elements, many works in different fields have been conducted to increase more detailed information to create semantically rich information models. Muller (2015) utilized GIS modelling in modern residential areas and developed the CGA and CGA++ shape grammar language for the procedural modelling of architecture. Tang et al. (2010) surveyed techniques developed in civil engineering and computer science that can be utilized to automate the process of creating as-built building information models. However, the works cannot deal with the irregular historic elements.

Historic building information modelling is one of the most serious issues that face many experts in the as-built modelling field. Murphy et al. (2007) firstly defined the Historic Building Information Modelling in 2007, which clearly expressed the prospects of BIM technique in historic scenes. The historic building is composed by the complicate and irregular architectural elements, while it has to be accurately and adequately represented with the structural elements of its geometry, attribute and semantic structuration to build a helpful 3D model. The historic buildings are still problematic while the modern buildings have been yet developed with good boundary information. Most of current (semi-)automatic 3D reconstruction works assumed the regular plane characteristic of buildings (Brenner, 2005), so that historic buildings are mostly excluded. In general, the specificity of historical components makes this task very difficult.

In one hand, modern surveying techniques have been widely complemented to realize 3D surface modelling of complex historic architectural scenes (Tang et al., 2010). Photogrammetry has been used for historic modelling for a long time, upon which dense point clouds describing the object surface can be obtained and ortho-images are used for texture mapping. However, dense image matching becomes more complex to deal with irregular historic objects. Laser scanning directly delivers dense point clouds suitable for 3D surface modelling. Point clouds obtained by laser scanning and imaging techniques are widely used in historic 3D modelling from the early visualization based models to the information enriched models (Remondino \& Rizzi, 2010; De Luca, 2006). The key differences of the information models compared with the visualization models is that they are constituted of elements which were classified by using a process of recognition and labelling of geometric primitives extracted from point clouds.

On the other hand, there exists some historic documentation about the heritage. According to the documentation data, the recreating process is just like the BIM process, by parametric modelling the elements and establishing the relations and then integrating the whole detailed building. In general, the commercial BIM tools can help to accomplish this process. ArchiCAD GDL language is used to build irregular and specific element library composing the historic objects (Fai \& Rafeiro, 2014). Although it is usually a manually time-consuming concept in BIM software to parametrically model the historic elements, the spatial relationship can be incorporated automatically in the modelling process.

Once the enriched historic models are constructed, the models can be managed. GIS environment represents a common information system for the representation of 3D urban objects. CityGML is there a widely used data format and structure, in which the most relevant topographic objects in cities and their relations are defined, with respect to their geometrical, topological, semantic and appearance properties (Agugiaro et al., 2011). GIS platform is used to manage and analyse the enriched information in historic models. Anyway, the 3D models in GIS may be built from different BIM or other 3D modelling platforms, and have been originally developed for modern buildings. Therefore, many researchers deal with the management of the complex and irregular elements in GIS, and the conversion between BIM and GIS (Saygi \& Remondino, 2013).

Till now, the common process to heritage information modelling consists of (i) point cloud acquisition, segmentation and geometry extraction, (ii) BIM parametric modelling and (iii) GIS management. Typical work by Murphy et al. (2013) proposed the common procedure combining the documentation and laser scanning data, BIM platform and GIS environment. BIM software is firstly used to build the parametric elements about the built historic building based on documentation. The parametric objects are then mapped into the point cloud or image survey data to be refined and finally a reality-based accurate model can be obtained. After the creation of the 3D model, it may be integrated into 3D GIS for further analysis.

\section{OPEN ISSUES}

There is a long road for enriched historic modelling to become mature. Many existing techniques from BIM, GIS, 3D graphics, Computer Science and Remote Sensing could help the modelling processing from different data sources to the final different level of detailed information model (Figure 1). Whereas, some key issues should be well addressed when introducing the existing methods into the historic buildings.

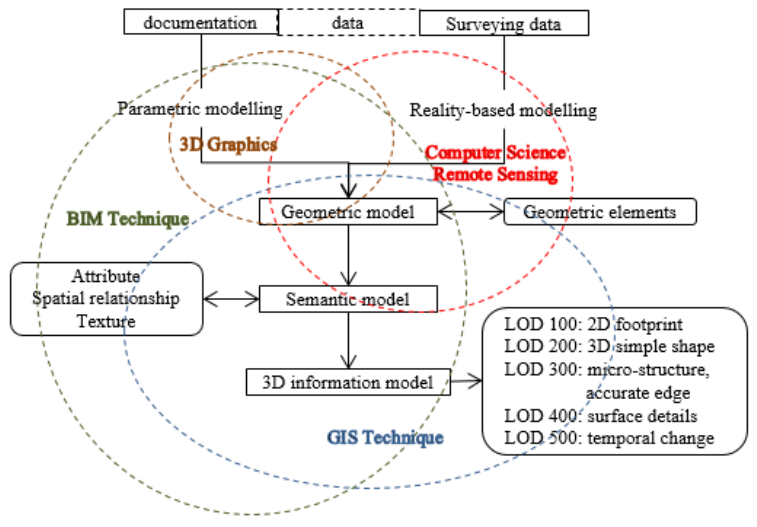

Fig. 1: The overall scheme of enriched heritage modelling with combined techniques 


\subsection{How to deal with the complex elements composing} historic buildings?

The first challenge comes to the complex elements composing the historic buildings, which makes historic architecture special compared to common and classical models and limits the application of commercial software aiming at regular geometry. In the one hand, the irregular and special elements do not exist in object libraries (IFC) and therefore cannot be directly included in usual BIM software. In the other hand, GIS are conceived to deal with simple 3D elements, and not for archaeological or historic models/sites, so that managing and analysing of complex 3D models can be generally problematic. So it can be profitable to use the capabilities of both BIM and GIS platforms to achieve the integration of a complex 3D building. But the complexity of many elements and the lack of unified criterions makes it difficult to simultaneously minimize information losing and optimize geometric architectural conservation while the exchange process between the two kinds of information systems. It benefits to information consistency among the different BIM software, GIS software and other modelling software if the representation of the complexity of the irregular shapes of the elements tends to be simplified. Unfortunately, when the simplification has lost the details of architectural surface, it goes against the aim of heritage conservation and may result in an un-useful model.

Till now, there exist three ways to parametrically model the irregular elements non-included in the BIM library: (i) The first one is the manually modelling of the elements in BIM software environment (Revit, ArchiCAD) (Aubin, 2013). The main drawback is its low efficiency and hard to assure the geometric accuracy. (ii) The second is the widely used programming Geometric Description Language (GDL) of ArchiCAD library parts (Martens \& Peter, 2002). The parametric GDL elements could be completely described as 2D symbols, 3D geometric models, attribute specifications and additional spatial relationships. (iii) The third is to build models with the help of 3D Graphics Software (Barazzetti et al. 2015), which could deal with any irregular shape object accurately compared to BIM platforms. As example, Rhino software is able to generate accurate models of complex and irregular geometries especially using NURBS for representing surfaces (Oreni, 2014). BIM software could then add and manage the attribute and spatial relationship information. So an obvious question arises: how to convert the Rhino NURBS based shapes into BIM parametric elements without losing information?

Once an enriched historic model with fusion of information is acquired from multiple modelling resources including BIMs, it is preferable to input it into the GIS environment to manage the attribute, spatial and temporal information. Therefore, three distinct fields (3D graphics, BIM, GIS) are dedicated to create digital representations of the real historic objects, although they focus on different aspects of historic building information management.

The separate standards, for instance IFC for BIM and CityGML for GIS, seem to be widely accepted, but it is critical to minimize the information loss in the conversion process (ElMekawy et al., 2012; Saygi et al., 2013). It means that the information loss mainly occurs in the irregular objects conversion from 3D graphic and BIM model to GIS environment. The BIM software are developing some plug-ins to help the conversion process or the integration of 3D graphics. And many works have been done to minimize the information loss in integrating of BIM and GIS. The common process is to extend the models from BIM to GIS, and a CityGML extension called GeoBIM to get semantic IFC data into GIS context is well developing (De Laat and Van Berlo, 2011). BuildingSMART IFC is also extending itself for GIS project application, such as the new entity for spatial zones, geographic elements and external spaces (Przybyla, 2010). Anyway a united system without information loss is not foreseen.

In conclusion, critical aspects and barriers in the case of complex object modelling need to be further investigated to handle detailed models of irregular historical objects.

\subsection{How to build geometric and spatial information enriched historic model?}

Nowadays, many techniques help the geometric modelling of historic buildings including BIM technique, GIS modelling, remote sensing technique, 3D computer graphics and computer vision. According to the data source representing the historic object, the current methods could be divided into documentation-based approach, reality-based approach, and the combination approach (See Figure 1).

\section{(1) Documentation-based approach}

Documentation-based approach is non-real measurement based approach utilizing BIM parametric modelling and 3D computer graphics techniques referring to existing documentation. It is meaningful and feasible to reconstruct the ancient landscape or re-create the ruined sites based on the preserved historic documentation and by using document re-interpretation when there are no usable indications in the documentation (Figure 2). Using historical data to re-create the past has been a hot topic in 3D computer graphics, while the aim is mostly for visualization and to build a $2.5 \mathrm{D}$ model. Typical work comes from the "Roma Reborn" project (Dylla et al., 2008), which re-represent the ancient Roma based on historic photos and data records.

Documentation-based approach is actually in accordance with the BIM concept, considering it generates a "new" historic building from the parametric elements to the whole entity possessing attribute and spatial relationship features. Moreover, the life-cycle characteristic makes BIM software suitable to the temporal and dynamic changing research about the historic objects.

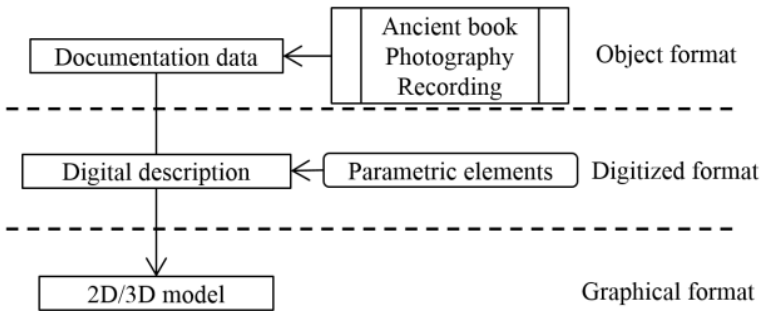

Fig. 2: The processing of documentation-based Historic

(2) Reality-based approach modelling approach

Creating 3D models for historic objects based on 3D drawing is a time consuming process. Reality-based modelling can rapidly collect the related representation data with photogrammetry and laser scanning, by which the image texture and 3D point cloud covering the surface of the object could be easily obtained. Traditional photogrammetry has paid attention to building reconstruction either to texture mapping and $3 \mathrm{D}$ modelling. Commonly used laser scanning provides accurate point clouds to replace the complex image dense matching. It is no doubt to take them together and supplement each other, and the concept of "combination" of 3D models derived from photogrammetry and laser scanning basically stay in two ways: the point cloud obtained by laser scanning could be textured from image data to 
create a virtual 3D model; the aligned and triangulated point clouds serve as a DEM to help to produce the orthophotos (Guarnieri et al., 2006).

Laser scanning is a fundamental tool for accurate surface modelling, but due to masks in certain field configuration it could not provide complete information. As for historical buildings, for example the church which is typical with complex edges, it is not the advantage of laser scanning point cloud (Rabbani et al., 2004). Image processing has the advantage of corner/linear feature extraction and matching, which could help to obtain the accurate information about the typical edge information. However, there is few related works till now to combine the image feature matching to point cloud in accurate historic modelling.

The problem is how to recognize and classify each point datum to corresponding element and eliminate the noise. The approaches are concluded in two types (Borenstein \& Ullman, 2008) (Figure 3): (i) Top-down method. The object is firstly recognized from its background using prior knowledge about its possible appearance and shape and then segmented to the subelements. (ii) Bottom-up method. The homogeneous primitives are firstly segmented, then combined into the semantic elements, and finally reconstruct the whole model based on spatial relationship. Unlike documentation-based model being a volume element model, the reality-based approach is a surface reconstruction, that is, it may be better to respectively model the building in indoor and outdoor scenes.

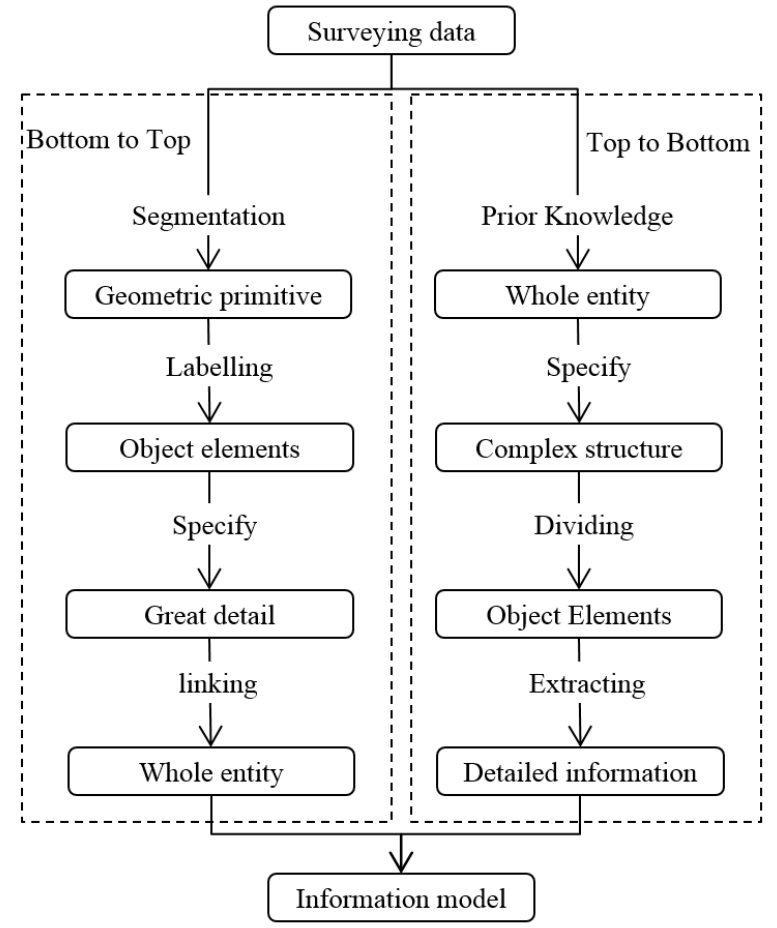

Fig. 3: The processing of Reality-based Historic modelling approach utilizing bottom-to-up and up-to-bottom approach

\section{(3) Combination approach in combined libraries}

As for the historic building, detailed documentation possibly exists, whereas the real form and shape is changed and is different from the documentation. In this case, the documentation-based 3D model is somewhat different from the reality-based modelling. Anyway, they are just the two different data processes dealing with the same object, so that combining together helps to refine each other. In one hand, the non-real model could serve as an initial template to help the recognition and segmentation of the reality-based model. In another hand, the same non-real model is refined once the point cloud data modifies the shape and form of the elements with the current surface morphology.

Considering the both different source of data and various modelling method, the enriched historic information modelling could be a system which consists in multiple libraries such as parametric object library, rule library, knowledge base, feature library, geometric primitive library (Figure 4).

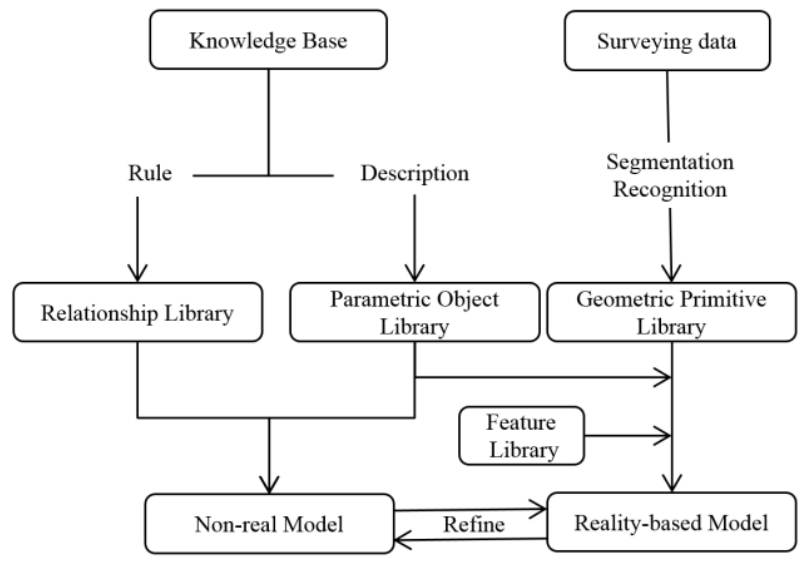

Fig. 4: The historic building modelling system

Knowledge base: Prior knowledge is the basis of build the parametric elements by parametric modelling and rules for procedural modelling (Figure 5). The knowledge library includes the digitalized historic manuscripts and architectural pattern books. It could also help the recognition and modelling process to address the point cloud.

Parametric object library: Parameterization of the architectural elements is the essential characteristic of BIM. The parametric object could be obtained by commercial BIM software (simple and regular shapes) and corresponding plug-in (Dynamo in Revit), scripting language $(G D L)$ or special graphic software (Rhino) for irregular elements. The parametric objects are dynamic in some extent and can instantly alter the shape, size and other properties by tuning parameters (Figure 6).

Relationship library: The elements could be incorporated together based on BIM platform or automatic rule-based procedural modelling. In this case, the building model could be generated by combining the parametric object library and rule library which are just controlled by user parameters (Figure 7).

Geometric primitive library: Geometric primitive is obtained by point cloud or image segmentation. Compared with the parametric elements, which are block-based changeable units, the segmented geometric primitives describe the surface features of the historic objects.

Feature library: The segmented primitives should be recognized and re-organized to the whole entity. It is first thing to describe the geometric primitive with distinguishable features. Once feature library is built, lots of machine learning approaches could help automatically to realize 3D modelling. The historic buildings under the same architectural style present similar features. Once some buildings have been modelled, they could serve as training data and build the corresponding feature library to model the similar objects automatically. Meanwhile, the parametric elements could be mapped into the point cloud to help the modelling processing based on dynamic template matching. 

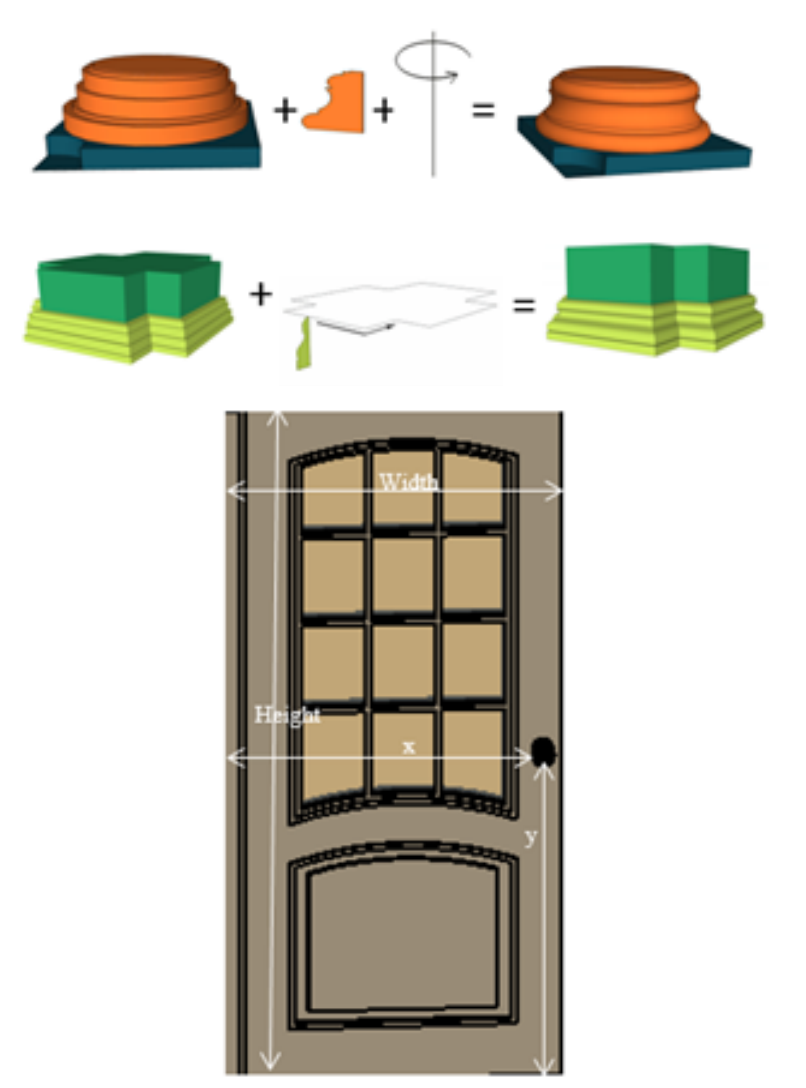

Fig. 5: The description information about the elements could be obtained from documentation data and then digitized to parametric object library.

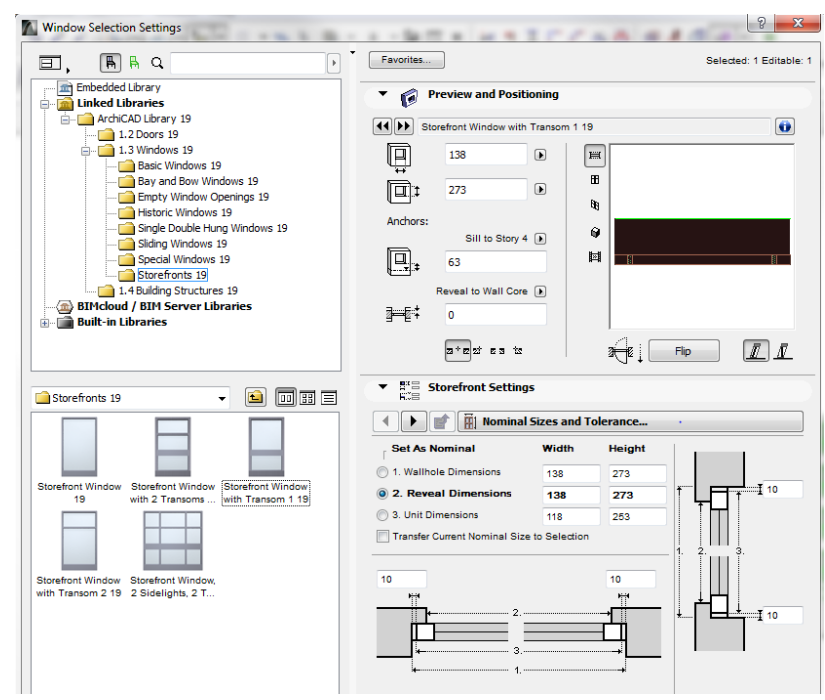

Fig. 6: Parametric window in ArchiCAD. The information about the window could be modified by the users.
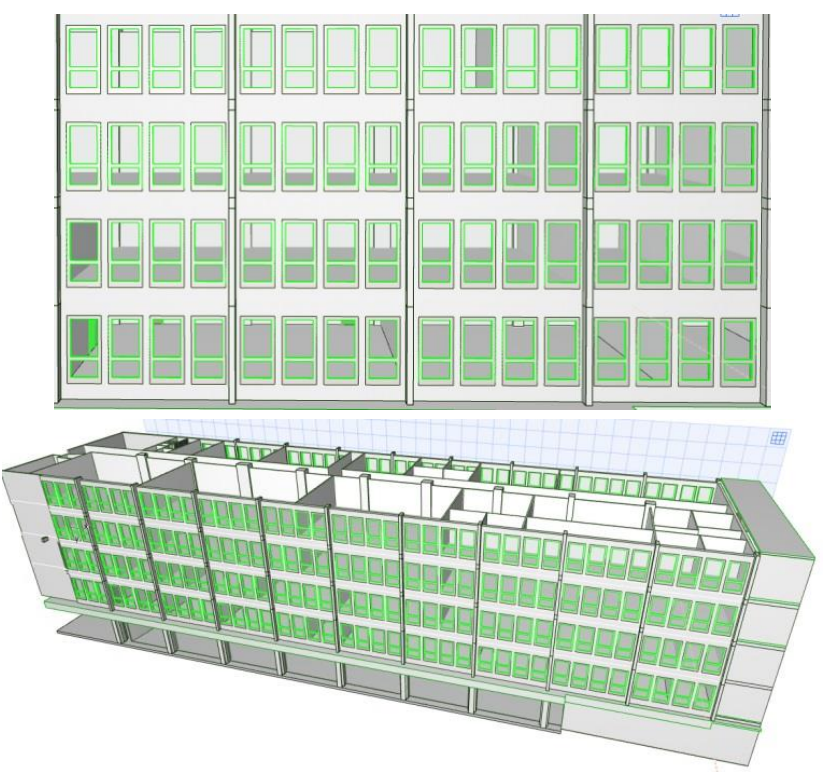

Fig. 7: The modelling process by linking the sub-elements.

3.3 Why building different Level of details and consider multi-scale problem?

One of the most talked about topics around enriched 3D modelling is always Level Of Detail (LOD). LOD is how deep in detail is the model element and a measure indicating their grade and scale. Therefore, different 3D modelling techniques focusing on different aims have different definitions about LOD. GIS field takes buildings combined with road, trees, bridge as basic elements, while BIM field take building as the whole entity and take the compositional structures such as column, openings as the basic elements.

CityGML has defined the LOD as five levels from LOD0 to LOD4, which has been widely accepted in modern building geometric modelling. LOD0 is as the cadastral map indicating the footprint of the buildings or a Digital Terrain Model (DTM) with an ortho-image projected on it. In LOD1 buildings are generalized in rectangular block generated by adding the height information. LOD2 provides additional details of roof and façade with different shapes (multi-polygon, gable roof, camber surface). LOD3 provides the façade sub-structures (windows and doors) and roof superstructures. LOD4 goes further to the indoor scene objects from the surface model. Therefore, CityGML take buildings as the basic element, it ignores the details of the micro-structures composing the buildings.

In the BIM field, there is no uniform definition about LOD. LOD is also defined as Level Of Development (LODt) in BIM by the American Institute of Architects (AIA, 2013), which verifies the model information that is required at each stage of development of the project and decides whether to continue to be the next stage or not. It focuses on the time scale and development of a new architecture. Similar to the CityGML focusing on the spatial details, PAS 1192-2 (BSI, 2013) defines LODt to consist of LOD (the graphical content) and Level of Information (the non-graphical content). LOD100 indicates there is an object, LOD200 add its size information, LOD300 add its additional functions and options information, LOD400 describe the object in accurate geometry, and LOD500 define the object in particular data. Anyway, the generalized LOD in BIM identifies how much information is known about a building element at a particular stage of the project (Cheng et al. 2015). 
LOD in GIS and BIM both serves for the own application, which are not totally appropriate for historic models. CityGML is dedicated to modern urban buildings and considers the information details in the stand of buildings, so it contains not enough description possibilities for the micro-structures. The historic building consists in complex elements mostly in irregular shape and various sculptures in surface or raised structures, which need to be accurately modelled. BIM is originally for new buildings. Level of Detail and Level of Development (which may be even more useful) focus on the time dimension for the construction stages. Historic BIM is as built BIM for the existing heritage. The LOD in BIM or GIS is then not suitable in Heritage BIM where relevant criteria are expected.
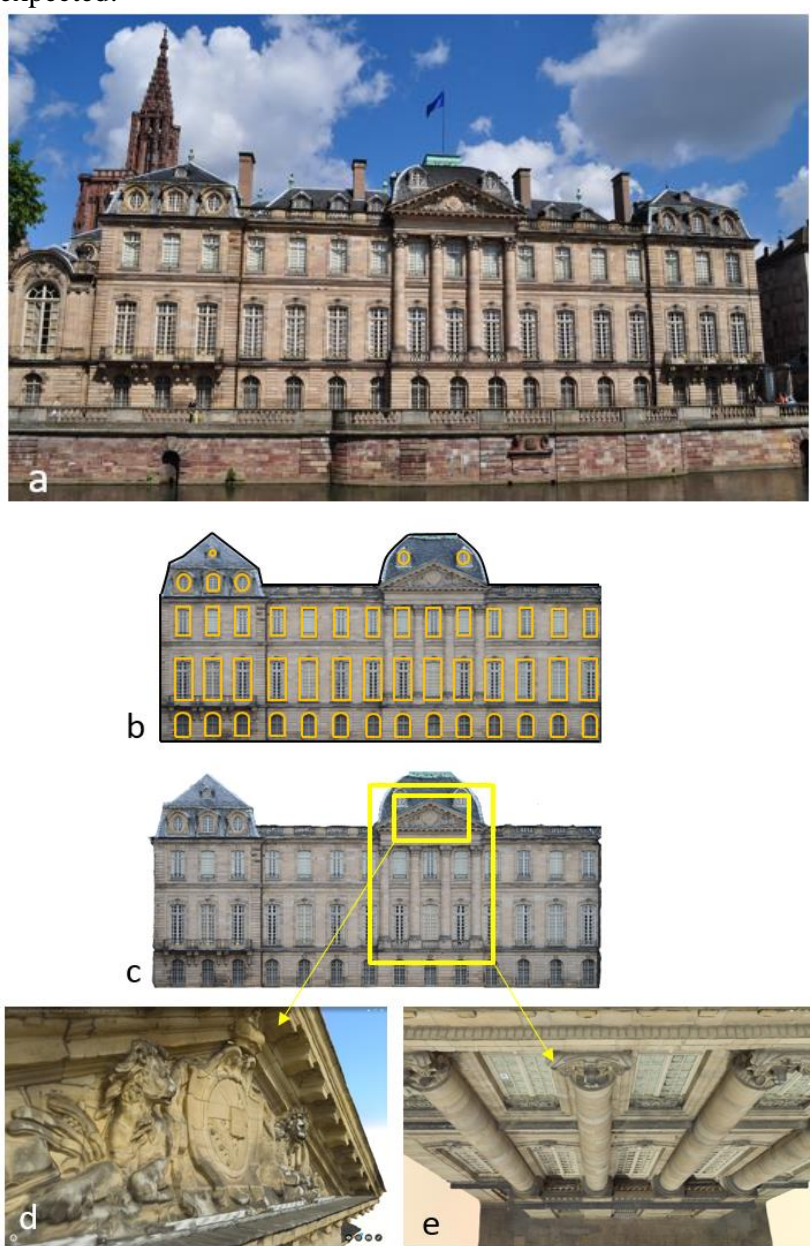

Fig. 8: The LOD for historic model taking a drawing and 3D modelling as example. LOD200 (b-c) represents the historic building facade with flat planes; LOD300 (b) provides the opening information; LOD400 provides detailed information such as accurate edge, the sculptures in the surface (d) and 3D columns, margins and windows (e).

The "detail" in historic building information modelling is how complex, accurate and changed about the elements, considering the specific spatial and temporal scale characteristics about the heritage. In the aspect of spatial information, the 3D historic models are being generated at different levels of detail and scales ranging from areal sites to individual building and to archaeological complexes using methodologies based on different accurate data acquisition techniques. The historic site firstly may consist in several buildings, which means it is not a mono-building problem. Then the building in different level of details is necessary to be considered, from a box to different morphology of roof/façade and then to the opening structures and finally to possible indoor structures. Moreover, the heritage is used to being sculptured to many micro-structures around the surface such as Statues or animals, which makes it more difficult to be reconstructed. Besides, it is expected to manage the heritage based on the enriched historic models, so that it is highly anticipated to cover the change information.

A LOD definition for historic models considering its characteristics could be defined here (Figure 8) (we used a parallel numbering as in BIM):

LOD 100: the 2D outlines of different historic building, which means that the building is considered as an historic building.

LOD 200: the simply models (but not box models) with size and basic shape.

LOD 300: the detailed model with sub-structures including openings and roof superstructures in 2D and 3D.

LOD 400: the accurate model with detailed structures such as the sculptures in the surface and complex shape about the openings (3D).

LOD 500: the temporal model indicating the changes of historic elements.

\section{CONCLUSION}

The state-of-the-art in the creation of enriched historic modelling combining BIM and GIS is generally beginning with a manually time-consuming process. This paper covers some open issues faced in the historic building information modelling process. Historic building is characterized by its complexity while it is necessary to accurately build an information-rich model for applications. BIM and GIS, the two distinct fields, are integrated to help the modelling of the historic buildings. Because of the lack of dealing with the complex elements, both of them need to be developed to be applied to the irregular structure modelling and it is necessary to minimize the information loss in the conversion process. A framework combining the documentation-based modelling and realitybased modelling is discussed. The parametric/procedural based non-real model and the object-recognition based model could refine each other to obtain an accurate historic model with ancient and current states, although it is still short of universal and automatic approaches. In the 3D modelling, creating different Levels Of Details (LOD) is not only to satisfy the different users' needs, but also to be conducted specifically in the modelling processing. There is no uniform criterion about the LOD for historic modelling like CityGML or BIM, which also have to be considered when converse the BIM model into GIS environment.

In conclusion, the paper summarized the integrated framework to accurately model the information-enriched historic building. Once the documentation is available, the documentation-based approach and reality-based approach could refine each other to obtain an accurate geometrical model.

If only the reality-based surveying data are available, the difficulty of accurate modelling of historic building increases. The parametrical modelling with BIM software, procedural modelling in GIS modelling and the machine learning will have a role to reduce the manual operation.

\section{ACKNOWLEDGEMENT}

The authors would like to thank Arnadi Murtiyoso and Drone Alsace for providing historic building images.

This research is supported by China Scholarship Council. 


\section{REFERENCES}

Agugiaro, G., Remondino, F., Girardi, G., von Schwerin, J., Richards-Rissetto, H. and de Amicis, R., 2011. Queryarch3D: Querying and visualising 3D models of a Maya archaeological site in a Web-based interface. Geoinformatics FCE CTU, 6, pp. $10-17$.

American Institute of Architects, 2013. AIA Contract Document G202-2013. Building Information Modeling Protocol Form, http://www.aia.org/digitaldocs.

Arayici, Y., 2008. Towards building information modelling for existing structures. Structural Survey, 26 (3), pp. 210-222.

Aubin, P. F., 2013. Renaissance Revit: Creating Classical Architecture with Modern Software, G3B Press, Oak Lawn, USA. 457 pages.

Barazzetti, L., Banfi, F., Brumana, R. and Previtali, M., 2015. Creation of Parametric BIM Objects from Point Clouds Using Nurbs. The Photogrammetric Record, 30 (152), pp. 339-362.

Bentley (2016). Multi-discipline Building Design and Analysis Solution.

https://www.bentley.com/en/solutions/multi-discipline-

building-design-and-analysis.

Borenstein, E. and Ullman, S., 2008. Combined topdown/bottom-up segmentation. Pattern Analysis and Machine Intelligence, IEEE Transactions on, 30(12), pp.2109-2125.

Brenner, C., 2005. Building reconstruction from images and laser scanning. International Journal of Applied Earth Observation and Geoinformation, 6 (3), pp. 187-198.

BSI, 2013. PAS 1192-2:2013 Specification for information management for the capital/delivery phase of construction projects using building information modelling.

http://shop.bsigroup.com/Navigate-by/PAS/PAS-1192-22013/.

Cheng, H.M., Yang, W.B. and Yen, Y.N., 2015. BIM applied in historical building documentation and refurbishing. The International Archives of Photogrammetry, Remote Sensing and Spatial Information Sciences, 40 (5), pp. 85-90.

De Laat, R. and Van Berlo, L., 2011. Integration of BIM and GIS: The development of the CityGML GeoBIM extension." In Advances in $3 D$ geo-information sciences, Springer Berlin Heidelberg, pp. 211-225.

De Luca, L., Veron, P. \& Florenzano, M., 2006. Reverse engineering of architectural buildings based on a hybrid modeling approach. Computers \& Graphics, 30 (2), pp. 160176.

Dylla, K., Frischer, B., Müller, P., Ulmer, A. and Haegler, S., 2008. Rome reborn 2.0: A case study of virtual city reconstruction using procedural modeling techniques. Computer Graphics World, 16, 6 pages.

El-Mekawy, M., Östman, A. and Hijazi, I., 2012. A unified building model for 3D urban GIS. ISPRS International Journal of Geo-Information, 1 (2), pp. 120-145.

ESRI (2016). What is GIS.

http://www.esri.com/what-is-gis

Fai, S. and Rafeiro, J., 2014. Establishing an Appropriate Level of Detail (LoD) for a Building Information Model (BIM)-West Block, Parliament Hill, Ottawa, Canada. ISPRS Annals of the Photogrammetry, Remote Sensing and Spatial Information Sciences, 2 (5), pp. 123-130.
Gabellone, F., 2009. Ancient contexts and Virtual Reality: From reconstructive study to the construction of knowledge models. Journal of Cultural Heritage, 10, pp. e112-e117.

Guarnieri, A., Remondino, F. and Vettore, A., 2006. Digital photogrammetry and TLS data fusion applied to Cultural Heritage 3D modeling. The International Archives of the Photogrammetry, Remote Sensing and Spatial Information Sciences, 36(part 5), 6 pages.

Martens, B. and Peter, H., 2002. Developing Systematics Regarding Virtual Reconstruction of Synagogues. ACADIA 2002 Conference Proceedings, Pomona (USA), pp. 349-356.

Murphy, M., McGovern, E. and Pavia, S., 2007. Parametric Vector Modelling of Laser and Image Surveys of 17th Century Classical Architecture in Dublin. In VAST 2007, pp. 27-29.

Murphy, M., McGovern, E. and Pavia, S., 2013. Historic Building Information Modelling-Adding intelligence to laser and image based surveys of European classical architecture. ISPRS journal of photogrammetry and remote sensing, 76, pp.89-102.

Oreni, D., Brumana, R., Della Torre, S., Banfi, F., Barazzetti, L., Previtali, M., 2014. Survey turned into HBIM: the restoration and the work involved concerning the Basilica di Collemaggio after the earthquake (L'Aquila). ISPRS Annals of Photogrammetry, Remote Sensing and Spatial Information Sciences, 2 (5), pp. 267-273.

Przybyla, J., 2010. Report on the EcoBuild Conference Introduction "Introduction to BIM-GIS intergration", Washington, DC https://www.nibs.org/?page=bsa_gisbimie (7 Dec. 2010)

Rabbani, T. and Van Den Heuvel, F., 2004. 3D industrial reconstruction by fitting CSG models to a combination of images and point clouds. International Archives of the Photogrammetry, Remote Sensing and Spatial Information Sciences (ISPRS), 35 (B5), 6 pages.

Remondino, F. and Rizzi, A., 2010. Reality-based 3D documentation of natural and cultural heritage sites techniques, problems, and examples. Applied Geomatics, 2 (3), pp. 85-100.

Saygi, G. and Remondino, F., 2013. Management of Architectural Heritage Information in BIM and GIS: State-ofthe-art and Future Perspectives. International Journal of Heritage in the Digital Era, 2 (4), pp. 695-713.

Saygi, G., Agugiaro, G., Hamamcioglu-Turan, M. and Remondino, F., 2013. Evaluation of GIS and BIM roles for the information management of historical buildings. ISPRS Annals of Photogrammetry, Remote Sensing and Spatial Information Sciences, 2 (5)/W, pp. 283-288.

Schwarz, M. and Müller, P., 2015. Advanced procedural modeling of architecture. ACM Transactions on Graphics (TOG), 34 (4), Article $\mathrm{n}^{\circ} 107$.

Tang, P., Huber, D., Akinci, B., Lipman, R. and Lytle, A., 2010. Automatic reconstruction of as-built building information models from laser-scanned point clouds: A review of related techniques. Automation in construction, 19 (7), pp. 829-843. 